during trephination must, therefore, be regarded as the danger signal indicating the urgent necessity of relieving the intracranial pressure.

\section{TOTAL ENUCLEATION OF THE PROSTATE FOR RADICAL CURE OF ENLARGEMENT OF THAT ORGAN.}

A FURTher series OF 119 cases of the operation. By P. J. FREYER, M.A., M.D., M.СH., SURGEON TO KING EDWARD VII'S HOSPITAL FOR OFFICERS, AND TO
ST. PETER'S HOSPITAL.

IN my last paper on the subject of total enucleation of the prostate, published in the British Mrdical Jodrnal of October 7th, 1905, I dealt with a series of 96 cases of the operation performed by me during the year ending July 20th, 1905, and concluded with a brief review of the results obtained in 206 cases of my operation performed by me down to that date. During the period that has elapsed since my return from my holiday on September 6th, 1905, to the end of July, 1906, I have operated on a further series of 119 cases, of which 30 were in hospital and 89 in private practice. The object of this paper is to place before the profession at large the results obtained from these operations. In my earlier series I gave full details of every individual case, and in my last two papers details of many of the cases, adding tables giving the date of operation, age of the patient, and medical man with whom seen or by whom sent, of each individual case. The present series is, however, such a large one that it is impossible within reasonable space to give in detail more than a few of the cases, illustrative of some important features of the operation. Where almost every case is replete with interest it is difficult to make a selection.

Case cCviI.

L., aged 60 , seen with Dr. $H$. Murray Norris (London), September 8th, 1905. Prostatic symptoms for three years; latterly intense frequency of urination and much pain. Catheter passed September 6th by Dr. Norris, and large quantity of residul and a large quantity of residual urine, which was alkaline drawn off Passed no urine subsequently except by catheter. I drew off $9 \mathrm{oz}$. residual urine, thick with pus and phosphates. Prostate enlarged to the size of a Tangerine orange, round, soft, movable. Patient very stout; intensely nervous. Next day there was much difficulty in introducing the catheter, which had to be tied in. Patient in great distress.

On September 11th, Dr. Norris assisting, I enucleated the prostate, which weighed $1 \frac{3}{4} \mathrm{oz}$, entire, with some difficulty, pwing to adhesions caused by cystitis. Several small calcul were imbedded in the substance of the prostate and remored therewith. There were about a dozen calculi in the bladder therewith. The

The ofient passed several ounces of urine per urethram on 0 tober 5th, and wholly in this way after October 11th. He left for home October 18th in excellent health and spirits, able to pass and retain his urine as well as he ever did. I saw this gentleman recently in perfect hualth.

I have noticed tuat prostates containing calculi embedded in their substance are more liable than others to be attended by severe cystitis, and that they are more difficult of enucleation owing to adhegions contracted with the sheath and mucous membrane of the bladder.

Case ccxitr

On May 15th, 1905, an American gentleman, aged 65, resident of New York, consulted me on the advice of Dr. Kraus of Carlsbad. Prostatic symptoms had existed eight years.
Catheter employed for six years, during which time patient was practically dependent thereon. Prostate much enlarged, bilobed, smooth, movable, and bimanually felt prominent in the bladder. Urgent business required his presence in America, so operation was postponed till his return in November, when there was much difficulty in introducing the catheter and the urine was putrid.

On November 29th, 1905, I enucleated the prostate entire Mr. C. Braine being the anaesthetist. The time occupied from commencing the suprapubic cystotomy till the prostate was delivered from the bladder was 5 minutes. The recover was uninterrupted. Some urine passed naturally December 15th, and next day the suprapubic wound was dry. On January 2nd 1906, he left the surgical home in excellent health, able to pass and retain urine, which was normal, as health, able to pass
well as he ever did.

The prostate (Fig. 1), which weighs $2 \frac{1}{2} \mathrm{oz}$., is of peculiar shape, presenting a gutter-shaped outgrowth in the bladder 2 in. long resembling an epispadian penis. This is the second prostate of this shape that I have removed.

CaSE CCLIV.

This gentleman, aged 75, consulted me, September 12th, 1905 on the advice of Dr. McAfee, West Kirby. Twenty years previously he had retention of urine whilst travelling in Italy. Catheter employed for three days, after which the urine was passed naturally till two years ago, when the catheter was resumed. Has had cystitis, orchitis, and haemorrhage occasionally. Residual urine $11 \mathrm{oz}$., containing much pus and mucus, though the bladder was washed out daily. Prostate enormously enlarged, bilobed, soft, movable. General health fair ; patient very stout, with tendency to chronic bronchitis. Operation advised but postponed at patient's wish.

On December 15th I was summoned to Crowborough to see the ratient with Dr. Basden. He had been confined to bed for nearly three months with cystitis, attended by rigors, high temperature tended by rigors, high temperature (105 F.) and delirium from time to time. Condition very feeble; pulse irregular and intermittent, advisable to undertake the operation at that distance. On Decemher 29th he was conveyed to undon by ambulance London by ampula but somew at improved, but stil feeble and flabby. On January 2nd, 1906, I enucleated the prostate entire, Dr. Basden, Dr. Adam Schmidt, Cbicago, being present. The prostate (Fig. 2) was the size and shape of an enormous pear, two-thirds of which projected in the bladder. The right lobe hed geveral nodular outgrowths. Weight $9 \frac{1}{4}$ oz. The enucleation was Weight $9 \frac{1}{4}$ oz. The enucleation was easy considering the size of the prostate and the stoutness of the patient, the time being seven morrbage, and the operation was well borne.

Progress was on the whole satisfactory, though slow during the early days after operation, but the urine was foul and there was nightly delirium. Had slight orchitis during the third was nightly delirium. Had slight orchitis during the thire week. When sitting up and convalescent, on February 18th, a sharp attack of bronchitis set in, for which I had the advantage of Sir Thomas Barlow's care of the patient. By March 2nd the patient was again out of bed. A small fistula remaining, I tied in a catheter for a week; after its removal the urine was passed naturally. By March 14th the wound was firmly healed and the patient walking about, able to pass and retain his urine, which was quite clear, as well as he ever did. The patient is now in excellent healtb. The case gave Sir. Thomas Barlow and myself much anxiety. Considering the patient's condition his complete recovery was remarkable.

\section{Case cClXI.}

Gentleman, aged 75, seen with ${ }^{-D r}$. R. Roche, London, Janary 3 rd 1906 . Prostatic symptoms had existed two years. Had retention in June, 1905 ; relieved by catheter, which had been irregularly employed ever since contained much pus. Latterly there had been much difficulty in introducing the catheter. For several days he had suffered from pyrexis, the temperature during the last two being $104^{\circ} \mathrm{F}$ with mental symptoms amounting almost to acute mania the result evidently of blood poisoning and uraemia. mania, the result evidenty to blo pear, being bilobed, smooth, dense, and very tender on pear, being bilobed, smo 
Owing to the pyrexia and mental symptoms I considered it advisable in the first instance to drain the bladder suprapubically, and later on, if these symptoms subsided, to complete the operation of removal of the prostate. Accordingly on January 4th I opened the bladder and inserted a large drainage tube.

On January 18th, the acute symptoms having subsided and the patient's general health having improved, I enucleated the prostate, which was pear-shaped with a plum-like outgrowth in the bladder from the right lobe; weight $2 \frac{1}{2} \mathrm{oz}$. Rapid recovery. Passed $16 \mathrm{oz}$. of urine naturally January $31 \mathrm{st}$ wound dry February 3rd.

On February 13th he went home in good health. On July 21st he wrote that he was perfectly well, able to pass and retain his urine as well as he ever did.

Amongst this series of 119 cases there were three instances in which, owing to the existence of certain conditions, I considered it advisable to drain the bladder temporarily before enucleating the prostate. Details of another of these cases will be given later on, to illustrate the varied conditions under which I regard this procedure as advisable.

Case cClXxx.

Gentleman, aged 84 , seen in consultation with Dr. P. L. Read, South Kensington, March 16th, 1906. Prostatic symptoms dated from seventeen years ago, when he was advised by a surgeon to use a catheter. He dispensed with this till a year ago, when cystitis accompanied by rigors and pyrexis set in and another pyrexia, set in, and anothe surgeon was consulted. Catheter employed four or five times daily till thre weeks previously, when he had to give it up owing to the pain and difficulty in its introduction. Condition very distressful ; great frequency of micturition day and night ; bladder much diston ' blader much distended. General health good. I passed a bicoudé catheter with difficulty, and drew off $15 \mathrm{oz}$. residual urine, thick with pus and mucus. Prostate greatly enlarged, bilobed, dense, mov able; felt bimanually the size of a large orange.

On March 20th, Dr. Read assisting, I enuclested the prostate (Fig. 3) entire, with prostant (Fig. 3) entire, with adherent thereto, easily and rapidly, the time occupied rapidly, the time occupied being five minutes. The patient scarcely felt any inconvenience from the operstion, and read the newspapers daily after the first day. Some urine passed naturally on April 8th, and the wound was closed on April 11th. He was sitting up out of bed on April 9th ap out of bed on April 9th, and went for a drive April from the date of operation he resumed business in the City, and is now

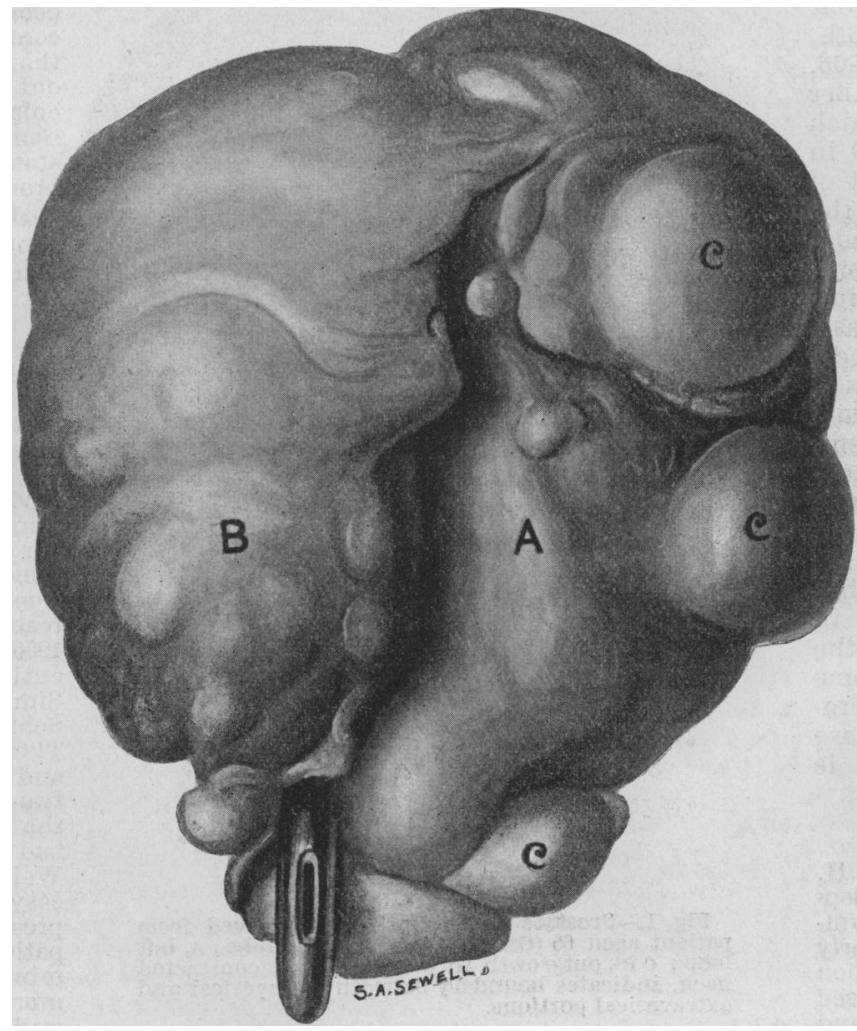

Fig. 2.-Prostate weighing $9 \frac{1}{4}$ oz., removed from patient aged 75 (Case
By March 21st the patient's health had markedly improved, and all the uraemic symptoms had disappeared, so on March rd I enucleated the prostate, which weighed $1 \frac{3}{4} \mathrm{oz}$, , entire in its capsule. On April 2nd some urine was passed naturally, and entirely in this way on and after April 6th. On April 27th retain his urine, which was normal, as well as he ever did. I

\section{Casr ccxcvil.}

A gentleman, aged 62, resident of Durban, came to England to consult me with a view to operation, on the advice of $\mathrm{Dr}$. A. McKenzie of that town. Prostatic symptoms had existed for four years. Catheter employed for three and a half years ; entirely dependent thereon for ten months. Prostate greatly enlarged, bilobed, dense, movable. On May 18th, 1906, I enucleated the prestate, which weighed $3 \frac{1}{0} \mathrm{oz}$., entire in its capsule, in five and $a$ half minutes. More bleeding than usual, but pulse kept slow and full. Uninterrupted recovery. Passed some urine per urethram June 1st; wound dry June 3rd. eft the surgical home June 22nd, passing and retaining urine naturally as well as he ever did. He is now in perfect health.

Case cCXcviri.

W. I., aged 74, has been a patient at St. Peter's Hospital on and off for eight years, suffering from enlarged prostate and vesical calculus. During that period he has had calculi removed by me by litholapaxy no less than fourteen times. Catheter employed for five yesrs; entirely dependent thereon for eighteen months. The urine during the last three or four years has been fetid, with a heavy deposit Two years ago I removed the right testicle for sloughing orchitis, but with no ptoms. Patient suffering ptoms. Pationt ath asthma; has mitral systolic and diastolic murmurs, with pronounced oedema of and flabby. Prostate greatly enlarged per rectum, the right lobe being more pronounced than the left, rather hard, and not very movable. During the movable. thought of enucleating the prostate, but the patient's prostate, but the patient's condition rendered him a subject for the operation. Latterly, however, his condition was so distressing, owing to difficultr in introducing the oatheter, that I decided on opersting the risks being fully placed risks being fully

On May 22nd, 1906, I opened the bladder suprapubically, and removed two phosphatic calculi the size of kidney beans. The prostate was then enuhe left the surgical home in perfect health, able to pass and have heard from him recently. He keeps quite well. plirely dependent thereon relief to the prostatic symthe lower limbs; very stout in excellent health, untroubled by any urinary symptoms. cleated entire in two and a half minutes. It presented The prostate (Fig. 3) weighs 71 oz A thin sheath (B, ) (Fith thereto. The letter $D$ is placed over the line of the anterior commissure, marking the separation of the lateral lobes, which were continued as irregular projections (c, $\left.c^{\prime}\right)$ in the bladder, were continued as irregular projections (c,
covered by the true capsule of the prostate.

Casir CCLXXXiri.

On March 2nd, 1906, a gentleman, aged 66, resident of Barcelons, consulted me on the advice of Ir. Heywood Smlth, London. Prostatic symptoms had existed for ten years, during which he had consulted various Spanish doctors. I found his bladder enormously distended with urine. He had not employed a catheter, but had almost incessant micturition day and night. He suffered much from thirst, dry tongue, day and night. He suffered much from thirst, dry tongue, constant, I find, with chronic over-distension of the bladder, and which, no doubt, are uraemic in origin. I drew off $65 \mathrm{oz}$. of pale urine of low specific gravity (1005), and containing pus, but I did not quite empty the bladder. The prostate was about the size of a Tangerine nrange.

On March 8th I opened the bladder suprapubically, and inserted a large drainage tube ; but I did not consider it advisable to remove the prostate till the uraemic symptoms should have passed off. a broad, tongue-shaped outgrowth in the bladder, and weighed $4 t \mathrm{oz}$ There was more haemorrhage than usual as $I$ almost invariably find in patients in whom calcul occur in connexion with enlarged prostate. The ansesthetic was badly borne, as on previous occasions with him during the litholapaxy operations, and he was much collapsed after the operation. He soon rallied, however, and was quite cheerful next day. The suprapubic wound was slow in closing. Some urine passed per urethram June 27th wound dry Jaly 5th; went home July 12th. He is now in good health the oedema having entirely dissppesred, and can pass and retain urine, which is clear, as well as he ever did.

This patient's recovery is, I submit, truly remarkable, considering the unfavourable state of his health at the time of operation, and indicates that patients should not be allowed to die in agony unoperated on even under the most desperate conditions.

Case CCCI.

An American gentleman. from Washington, aged 68, consulted me on May 23rd, 1906, on the advice of Dr. Gilchrist, of Nice. Prostatic symptoms had existed for fourteen years. Catheter employed for twelve years, latterly five or six times daily; severe haemorrhage from time to time. Prostate 
enormously enlarged per rectum, bilobed, smooth, soft, movable ; felt bimanually.

On May 26th, Mr. Thomas Nann, London, and Dr. G. Clarke, London, Canada, being present, I enucleated the prostate entire in six minutes. Scarcely any bleeding. The prostate, a fine, pear-shaped specimen, weighs $9 \frac{1}{4}$ oz.

Recovery uninterrapted. Some urine passed naturally un June 13th, and wholly in this way on and after June 14th He left the surgical home June $30 \mathrm{th}$, able to pass and retain urine normally. I saw the patient on July 17 th on his way urine normally. I saw the patient on July 17th on his way home to America. He was in perfect health, able to retain
urine from four to eight hours, and pass it as well as he ever did.

CaSe CCCVII.

A distinguished physician from the North of Ireland, aged 80 , consulted me on June 5 th, 1906 , on the advice of Sir James Dick, R N. Prostatic symptoms for fifteen years. Catheter, employed two years. In great distress from pain and constant desire to micturate, due to cystitis. Residual urine, $8 \mathrm{oz}_{0}$, contained much mucopus. Prostate greatly enlarged, bilobed, movable, and felt bimanually. Patient thin and in very feeble health owing to constant distress; suffering from chronic bronchitis. On June 7th, Mr.' Sherman Bigg being present, I enucleated the prostate entire with great ease, in four minutes. The prostate was trefoil and weighed $3 \mathrm{oz}$. Next day the patient was $3 \mathrm{oz}$. Next day the patient was so well that with difficulty I letters. Some urine passed naturally June 28th ; wound dry July 3rd. On July 7th he was walking about quite well, and able to pass and retain his urine, which was normal, as well as he ever was normal, as well as he ever "Since my prostate was removed I am a new man. I am not only free from pain and torture of fres from pain and torture of mal functions of the bladder are completely restored."

Case cccxi.

An eminent French physician came from Paris to consult me June 12th, 1906, with a view to removal of his prostate. Suffered from the usual prostatic symptoms for six years. Retention of urine two years ago; entirely dependent on catheter since then. Has had cystitis for months, orchitis several times, and he has been ungble to walk or drive owing to the poin and haemorrhage brought on by haemorrhage brought on by exercise. Prostate greatly enlarged, bilobed, soft, rounded, movable. As I decided on removal of the prostate, I did not put him to the pain of sounding him, but the presence of calculi was almost certain.

On June 12th, 1906, SurgeonGenerals J. Cleghorn and W. R. Browne, I.M. S., and Dr. Emery (Case ccLxxx). A, Right lobe; B, ieft lobe; , placed over anterior
of Toronto being present, I commissure, which is faintly seen through a thin band of the Browne, I.M.S., and Dr. Emery (Case ccLxxx). A, Right lobe; B, ieft lobe; D, placed over anterior
of Toronto being present, I commissure, which is faintly seen through a thin band of the removed 11 calculi. Weighing sheath removed with prostate; c c', outgrowth in bladder covered 915 gr., suprapubically, and then by true capsule. enucleated the prostate, which weighed $2+$ oz entire in its capsule

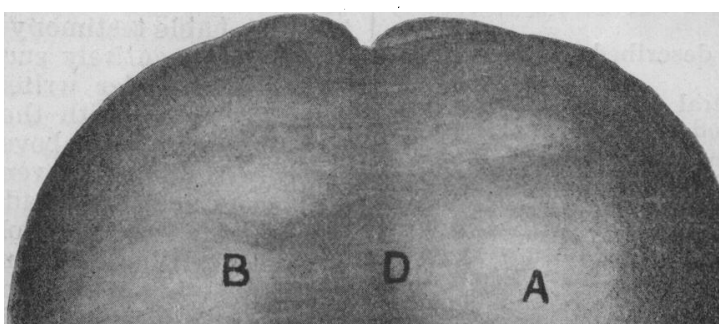
unfavourable symptom up to that time.

3. One from shock seven hours after operation.

4. Six from uraemic symptoms, from three to thirty-nine days after operation, in all of which the kidneys were extensively diseased before operation. One was found to be suffering from cancer of the bladder at the time of operation; and in one case the bladder was literally full of phosphatic calculi.

Though all these deaths are accepted as occurring in connexion with the operation, the fatal result in most of the cases occurred from diseased conditions previously existing rather than from the operation. With the exception of the patient that died from pulmonary embolisman accident liable to occur from any operation-they were all desperate cases, in which operative interference was postponed till catheterism could no longer be employed, and when the patients were practically moribund. But to refuse to operate in such instances would mean the sacrifice of many lives, as the details of cases in this and previous papers of mine fully testify. Amongst thees 119 cases I had a consecutive series of 39 operations without a death. Taking the advanced ages of the patients the subjects of this disease into consideration, I venture to say that there is no more successful operation in surgery in experienced hands, provided it be undertaken before the kidneys become seriously diseased.

In the April number of the Annals of Surgery for $1905, \mathrm{Dr}$. Eugene Fuller, of New York, lays claim to having been the originator of the operation which I have described as $\mathrm{my}$ own. A similar claim was advanced by him during the controversy that ensued on the publication of $m y$ first lecture on the subject in the British Medical Joureal of July 20th, 1901, and its absurdity demonstrated in the issue of that JoUnNaL of August 17th, 1901. I should not, therefore, consider it necessary to refer to the subject again, only that Dr. Fuller now publishes in support of his contention a somewhat belated letter, dated February 5th, 1905, written him by Dr. Ramon Guiteras of New York, in which this latter gentleman alleges that when passing through London in 1900 he explained to me Fuller's method of operating (1) Fourteen minutes elapsed from commencing the operation till the prostate was delivered of the calculi.

Uninterrupted recovery. Some urine passed naturally June 30th. On July 1st he passed $16 \mathrm{oz}$. at once in full stream and with great ease. The suprapubic wound being slow in entirely closing, a soft catheter was tied in from July 18th till July 24 th. On its removal, the whole of the urine was passed naturally. He walked and drove out July $26 \mathrm{th}$, and on August naturally. He walked and drove out July 26th, and on August 4th he returned to France in excellent health, able to pass
retain his urine, which was normal, as well as he ever did.

The ages of the patients varied from 50 to 86 years, the average age being $68 \frac{1}{4}$ years. The prostates weighed from $\frac{1}{2} \mathrm{oz}$. to $9 \frac{1}{4} \mathrm{oz}$, the average being a little over $2 \frac{1}{2} \mathrm{oz}$. In connexion with these 119 . operations there were 9 deaths, or $7 \frac{1}{2}$ per cent., the remaining 110 cases having been completely successful. The causes of death were:

1. One from jaundice on the fifteenth day, the case having been complicated with malignant disease of the liver.

2. One from pulmonary embolism on the fifth day. I and his own modification thereof; and then $I$ am accused of having published their combined method as my own without any reference to either of them.

It is true that I did not allude to the work of either of these gentlemen, for the simple fact that, as I shall presently show, there is no similarity between my operation and that described by Dr. Fuller, and that the "instruction" alleged to have been given me by Dr. Guiteras exists only in the imagination of that gentleman.

Dr. Fuller bases his claim to having originated the operation which $I$ regard as my own on an article published in the Journal of Cutaneous and Genito-Urinary. Diseases of June, 1895, entitled "Six Successful and Successive Cases of Prostatectomy." Turning to this article we was purely a partial prostatectomy of the McGill type, bearing no resemblance to mine.

In the operation described by Dr. Fuller-(1) a perineal section is made in addition to the suprapubic cystotomy; (2) the saprapukic wound is closed by decp and superficial find that not alone was the technique employed by Dr. Fuller radically different from mine, but that his operation 
sutures; (3) an attempt is made to render the prostate prominent in the bladder by pressure of the fist on the perineum; and (4) cutting anc crushing instruments are employed to attack the prostate, prominent amongst which are, to use Dr. Fuller's own words, "Rough serrated-edged scissors with a long handle," which are used " to cut through the bladder wall" in the region of the urethral opening, "the cut extending from the lower margin of the internal vesical opening of the urethre backward for an inch and a half," all of which proceedings and accessories are, it will have been observed, foreign to my operation.

Let us now examine Dr. Fuller's 6 cases in detail to ascertain the extent and nature of the prostatic substance removed in each instance, and see if this bears any resemblance to that removed by me as already described and figured. The description of what was removed will be given in Dr. Fuller's own words :

CASE A.-I removed a large right lateral hypertrophy and the median hypertrophy, which last was moderate. Owing to the bad condition of the patient I did not wnit to remove small left lateral hypertrophy.

CASE B. - I enucleated in the way described a large collarlike hypertrophy of the prostate.

CASE C. - l found two large lateral hypertrophies. The median hypertrophy was not marked. These hypertrophies were all thoroughly enucleated without difficulty.

CASE D.-Owing to the age (48 years) of the patient and the small size of the prostate as felt per rectum, it was not thought smacessary to being employed. As the result of the operation a very hard fibrous mass, similar in shape but smaller than a hen's egg, fibrous mass, similar in shape but smaller than a hen's egg, was found lying transversely across the floor of the bladder
just at the vesical neck. This was cut through by the knife in just at the vesical neck. This was cut through by the knife in making the perineal incision. It was, however, so fibrous and so firmly attached to the capsule of the prostate that it was found impossible to enucleate it, and it consequently had to be cut away by the use of both the serrated ecissors and of prostatectomy cutting forceps.

CASE E.-I enucleated two large lateral hypertrophies, together with a small median one, the whole mass coming away in one piece.

CASE F.-I enucleated two large lateral bypertrophies, together with a collar-like median hypertrophy, partially surrounding the urethra.

It is simply ludicrous to claim that these were total prostatectomies resembling that described and practised by me. One (Case D) is a perineal operation pure and simple. In one (Case A) Dr. Fuller "did not wait to remove a small left lateral hypertrophy"! They were one and all obviously partial prostatectomies, in which nodular lumps of enlarged prostate ("hypertrophies" Dr. Fuller calls them) were removed from within the capsule, as in McGill's operation; whereas the essential feature of my operation is that the prostate is enucleated entire in and with its capsule out of the enveloping sheath of rectovesical fascia. It was the discovery that this could be accomplished-contrary to the then accepted teachings of the anatomists-that constituted the essential novel feature in my operation. We can in consequence approach our task-that of removing the prostate entire, and the prostate only-by a simple and scientific plan of campaign, instead of the crude and unscientific methods previously practised by McGill and his imitators, in which scissors, cutting forceps, and scoops of all kinds were employed to cut and tear away portions of prostate leaving others behind, and frequently removing portions of the bladder and other tissues beyond the limits of the prostate, with such fatal results that for some years before 1901, when my operation was placed before the profession, these operations had been practically abandoned.

The objects figured as removed in cases $E$ and $F$ in Dr. Fuller's series are obviously mangled masses of prostate and bear no resemblance to the cleanly enucleated entire prostates figured by me, which to the number of over 300 have been preserved in my private collection or presented to public museums, and which have been seen and examined by scores of Dr. Fuller's countrymen. challenge again, as I have repeatedly challenged, the production of a single authentic specimen of entire prostate from any museum in the world, placed there before the publication of my first series of cases in July, 1901, with any published illustration thereof, or description of its having been removed entire in its capsule. There was no such specimen in the great Hunterian Museum of the London College of Surgeons till, at the request of the Curator, 1 presented a dozen specimens thereto.

Dr. Fuller's ic̉ea of what constitutes a total prostatectomy is not less strange than his conception of what constitutes a successful operation. Describing the condition of Case $\mathrm{E}$ he writes: "Four weeks after the operation the patient sat up, and now, six weeks after, he walks about the ward with the help of an attendant. The urine, now clear, still comes through the granulating suprapubic wound, which the slough made quite extensive. There is good expansive force in the bladder, and with the suprapubic wound closed I feel that urination will be accomplished without difficulty. The uraemic symptoms have not all disappeared, and at times he is drowsy. or excitable. It is probable that in time he will succumb to his nephritis, and such is to be expected, especially since, owing to his poverty, comparatively little can be done for him."

Let the reader imagine himself in the position of this patient, and say if, under the circumstances, he would regard the operation as successful. But what matters it what the reader thinks, since Dr. Fuller adduces the irreproachable testimony of Mr. Mayo Robson to the effect that it was entirely successful? In his article in the Annals Dr. Fuller writes: "Mr. Robson concludes his reference to me with the remark, 'Moreover, Dr. Fuller's cases referred to above were completely cured." I scarcely think that even the testimony of $\mathbf{M r}$. Robson will convince the reader that this case was either "successful" or "completely cured." Mr. Robson is evidently willing to extend to Dr. Fuller that elasticity as to the meaning of the word "success" which he employs in his own statistics, for in the British Medical Journat. of September 7th, 1901, p. 627, I pointed out that $\mathbf{M r}$. Robson had returned a case as "successful both immediate and remote" which had obviously died from operation. I have referred to this matter merely to show that Dr. Fuller's statements and statistics have to be taken with a certain amount of reserve.

Dr. Fuller quotes freely from the letters of my opponents in the controversy that ensued in the BRITISH Mrdical JoURNAL on the publication of the first four cases of my operation, and adds, "any one interested can read them." Yes, indeed, and interesting literature they will prove in the light of subsequent events. But considering the triumphant success of $\mathrm{my}$ operation, and vindication of the views I then enunciated, I would venture to suggest that, for the credit of the profession, a veil might be drawn over the misrepresentations, misstatements, and sophistry with which I was then assailed, when I stood practically alone-a fate which I have enjoyed in common with every pioneer of any great advance in surgery or medicine.

With reference to the statement contained in Dr. Guiteras's letter of February 5th, 1905, published by Dr. Fuller in his Annals, to the effect that when in London in 1900 , on his way to Paris, where he read a paper before the International Medical Congress on the present status of the treatment of prostatic hypertrophy, he met me and explained Dr. Fuller's method of operating, and his own modification thereof, I was not previously aware that I had had the honour of this gentleman's acquaintance. He does not state in his letter where the interview took place, but Dr. Fuller supplies the omission by locating it at St. Peter's Hospital, a fact that would indicate that this letter was not the only communication that passed between these gentlemen on the subject! I presume that, like scores of his countrymen-who are always welcome-he honoured me with his presence in the operating theatre. But I have no recollection of having ever conversed with him on prostatectomy or any other subject; and certainly if any such conversation did take place it left no impression on my mind.

It is fortunate, under the circumstances, that the paper read by Dr. Guiteras in Paris is published in extenso in the New York Medical Journal of December 8th, 1900, so that we are in possession of his views as to the nature and scope of Dr. Fuller's operation. After describing this operation, he writes

In this way the bulk of the prostate can often be shelled out in three large pieces, while at other times it must be removed piecemeal. Enucleation cannot always be performed by this means, and frequently the operator has to be content with the removal of a piece forming the principal part of the barrier.

This, then, would have been the gist of the imaginary "instruction" conveyed to me! I need scarcely say that 
the operation described, whether in its technique or in its scope, bears no resemblance whatever to that which bears my name.

Dr. Fuller published the description of his operation with 6 cases in June, 1895, but his teachings seem to have fallen on deaf ears. No one ever seems to have thought it worth while to point out the resemblance it bore to McGill's operation, which had then fallen into disfavour. So far as I am aware, his name was never referred to on this side of the Atlantic for more than six years after-till it was unearthed from the dusty archives of the Medico-Chirurgical Society by Mr. Mayo Robson during the controversy that ensued on the publication of my first lecture on my operation in July, 1901, and then only after the attempt by Mr. Robson to father my operation on him self had been exposed and refuted. I am not aware that in his own country it fared much better. Contrast with this the profound interest elicited by the publication of my first 4 cases of $\mathrm{my}$ operation; the extraordinary rapidity with which it has been adopted by surgeons all the world over; the irresistible conviction carried to the profession and public by the details of the several series, gradually increasing in number, since published.

\section{CASES OF \\ TETANUS TREATED WITH ANTITETANIC SERUM : RECOVERY. \\ I.-By W. WINSLOW HALL, M.D., M.R.C.S., LONDON.}

THE following case affords an example of the value of antitetanic serum:

A. B., aged 8 years, previnusly healthy, of a family prone to rheumatism and otitis medis, was brought to me on Augus 15th, 1906. It was said that his breath was offensive, and that he screamed at nights. The tongue, and the mouth generally, were swollen and sore.

On August 18th I saw him at his own bome. $\mathrm{He}$ had stiffness about the neck, and a slight risus sardonicus; but his father maintained that this painful smile was his natural expression; the pulee was good, and the temperature was normal. I could find no physical signs of disease other than the foul mouth. The bowels were cleared out with calomel, and potassium bromide gr. 5 was given every four hours. On August 19th the condition was unchanged. On August 20th the risus was more marked, and the parents volunteered an sccount of opisthotonos occurring during the night; the pulse was 72, the temperature 99.6. I I took the boy into St. Monica's Home Hospital ; there the mouth was carefully treated with boric acid, and afterwards with hydrogen peroxide. He was given chloral hydrate gr. 5 , and potassium bromide $\mathrm{gr}$. $7 \frac{1}{2}$, every two hours.

On August 21st it was reported that he had slept, but that spasms had occurred every ten minutes during the night. Risus sardonicus was unmistakable, as a spasm occurred in my presence, opisthotonos was equally unmistakable. He could swallow slowly, but with pain. Grey, pultaceous ulcers were visible over the tongue and cheeks, but full examination of the mouth was impossible, owing to rigidity of the jaws. The pupils were small and equal, and the eyeballs rotated The pupils were small and equal, and the eyeballs rotated
down. There was no otorrhoea, but the right membrana tympani was thickened and opaque. The skin reflexes in the abdomen and the lower extremities continued unduly brisk.

At 3 p.m. 60 c.cm. of antitetanic serum were injected in the iliac regions. The chloral and bromide mixture was given four-hourly.

On August 22nd the boy's condition had improved. There had been only 23 spasms in twent $y$-four hours, against some 96 in the preceding day and night. The temperature was $98.6^{\circ}$ the pulse remained strong, and was 100 to 108 ; the respirathe pulse remained strong, and was 100 to 108 ; the respira-
tions were 22 to 28 . The tongue was cleaner. Nourishment tions were 22 to 28 . The tongue was cleaner. Nourishment of antitetanic serum were injected. The chloral and bromide mixture was given two-hourly again.

On August 23 rd improvement continued. There had been twenty-two spasms in twenty-four hours. The temperature was normal ; the pulse and respiration the same as on the preceding day. The tongue was rather cleaner; the mind clear; the cremasteric and abdominal reflexes absent, the patellar and plantar reflexes were only moderate. An injection of $30 \mathrm{c.cm}$. was given again. On August 24 th the patient looked brighter; was given again. On August 24th the patient looked brighter ;
only eight spasms had occurred in twenty-four hours; the tongue was still cleaner, and he had swallowed two pints of milk since the preceding morning. On August 25 th only seven spasms had occurred. On the morning of August 26th there had been no spasms for over twenty-four hours. The sloughs were cleaning off the tongue. On August $27 \mathrm{th}$ the reflexes had reappeared up to the level of the epigastrium. The chloral and bromide mixture was given thrice daily. Spasms were still absent, nor, with the exception of one spasm at 2.30 .. $\mathrm{m}$. on August 31st, did they recur. The tongue cleaned gradually, but was not free from ulceration till September 10th. His convalescence was chequered by a rise of temperature to $102^{\circ}$ and $103^{\circ}$ on September 3rd and $18 \mathrm{th}$, and 21 st, along with an urticarial and erythematous rash. On September 14th he was carial and erythematous rash. On September 14th he was home. He is now at school, and is perfectly well.

The interesting points about this case are: First, the absence of any apparent inlet, except the foul mouth, for the germ; secondly, the slow development, and this bears on the happy issue of the case ; thirdly, the loss of weight ( $3 \mathrm{lb} .14 \mathrm{oz}$.) while the spasms continued, and the steady gain after they ceased; fourthly, the almost normal temperature while the convulsions were at their worst, and the high temperatures occurring later with antitoxin rashes; filthly, the treatment. Here it is noteworthy that, though the chloral and bromide made him sleep, they had no apparent action on the spasms; while diminution in number and intensity and length of spasm was evident at once after the use of antitetanic serum. The dose of serum given is also noteworthy. In all, $120 \mathrm{c.cm}$. were given; this required twelve separate punctures, and cost £2 8s. The authorities recommend $400 \mathrm{c.cm}$. in all, which would mean forty punctures, and a cost of $£ 8$; but surely few patients could stand this. It seems desirable that both the cost and the bulk of the remedy should be somehow lessened. Yet my conclusion is that in a case of tetanus, whatever the pain and whatever the cost, antitetanic serum should be fairly. tried, and with as little delay as possible.

\section{II.-By EUSTACE G. CARTER, M.R.C.S.EnG., CHAPEI-ALLERTON, LEEDS.}

Profeseor Sims Woodhrad, in Alltutt's System of Medicine, gtates: "Of those cases where the incubation period is under ten days not more than 3 to 4.5 per cent. recover; when the incubation period is still longer, about half the patients attacked throw off the disease." In the case described below the incubation period was seven to eight days, and belongs, therefore, to the more serious group. I think, therefore, to the antitetanus serum must be given the credit for the favourable termination of the case.

On the evening of July 24th, 1906, I was sent for to a young farmer aged 22 , who had fallen from a wall astride a dahlia stick, causing a lacerated wound of the scrotum, and exposing both testicles, which were otherwise uninjured. As is frequently the case in those that work on the land, the skin in the neighbourhood of the wound was extremely dirty, and it took a considerable time to cleanse it even comparatively; the wound itself was freely douched with a mercury biniodide solution, itself was freely douched with a mercury biniodide solution, suppurated, and at least a square inch of the scrotum sloughed, but there was no elevation of temperature or any other symptom of constitutional disturbance till the morning of August 1st, eight days after the accident, when he complained of stiffness about the angles of the jaws and difficulty in opening his mouth. Within four hours $I$ injected $10 \mathrm{c.cm}$. of antitetanus serum, prepared by the Lister Institute, under the skin of the abdomen. The general condition of the patient was good, temperature normal, pulse 72 , respirapatient

When I saw him on the following morning he had passed a restless night, the rigidity of the jaws was more marked, and accompanied by stiffness in the muscles of the abdominal wall and lower extremities. I injected $10 \mathrm{c.cm}$. of serum, and ordered $20-\mathrm{gr}$. doses of chloral hydrate and potassium bromide every four hours, to be discontinued if the patient became too somnolent; the same evening $10 \mathrm{c.cm}$. of serum were injected as before.

On the morning of August 3rd the nurse reported that the patient bad passed a restless night, and that he bad had several tetanic spasms. I found the general rigidity of the muscles of the jaws, abdomen, and thighs more marked, so I injected $20 \mathrm{c.cm}$. of serum, which as I inserted the needle produced a violent spasm, the patient being thrown into a condition of pronounced opisthotonos. There being no change for the better in the condition of the patient, I again injected $20 \mathrm{c.cm}$. of serum twelve hours subsequently. On August 4 th the nurse reported that for two or three hours after each injection of the serum the patient had fewer attacks of spasm, injection of the serum the patient had fewer atacks of sasm, therwise he remained much the same.

It is not necessary to give a detailed account of the progress It is not necessary to give a detailed account of the progress
of the case from day to day; the patient was now in the midst of the case from day to day ; the patient was now in the midst days ; that is to say, the last spasmodic seizure occurred on the twenty-eighth day after the onset of the trismus. For some days longer, however, there remaized some stiffness about the 